\title{
HCI Practices and the Work of Information Architects
}

\author{
Toni Robertson and Cindy Hewlett \\ Faculty of Information Technology, University of Technology, Sydney, PO Box 123 \\ Broadway NSW 2007 Australia \\ \{toni, chewlett\}@it.uts.edu.au
}

\begin{abstract}
We interviewed 26 information architects about their work, their backgrounds and their perceptions of their roles as information architects. Our research aimed to identify and understand the work practices that define the position of information architect as well as the human-computer interaction and usability issues that are relevant to their work. Our findings show that the work practices of information architects are far broader than those included in the popular technology design literature. A major issue that emerged from the research was the ongoing struggle of information architects to bring user-centred design methods into the design and development processes used in their organisations. A thorough knowledge of human-computer interaction and usability principles increased the ability of individual information architects to influence design processes.
\end{abstract}

\section{Introduction}

Information Architect: 1) the individual who organises the patterns inherent in data, making the complex clear; 2) a person who creates the structure or map of information which allows others to find their personal paths to knowledge; 3) the emerging 21 st century professional occupation addressing the needs of the age focused upon clarity, human understanding and the science of the organisation of information.

Richard Wurman, Information Architects (1996) p. 9

When I came up with the concept and the name information architecture in 1975, I thought everybody would join in and call themselves information architects. But nobody did-until now. Suddenly, it's become an ubiquitous term.

Richard Wurman, InformationAnxiety2 (2001) p. 24

A few years ago the job title, Information Architect, began to appear in recruitment advertisements for information technology (IT) design positions, mostly within web design environments and/or projects. Round the same time it began to be included, both anecdotally and in the textbooks, as one of the jobs that human-computer interaction (HCI) and usability professionals might do. For example, it is not listed in Preece et al., Human-Computer Interaction (1994) but it is in the later book, Interaction Design: beyond human computer interaction (2002), where information architects are defined as "people who come up with ideas of how to plan and structure interactive products, especially websites" (p. 11). It is the sudden use of the term information 
architect as if it named some established and well understood role that motivated the research reported in this paper. Who are the people who do this job? Where do they come from? What do they actually do? And where does the work they do fit within the wider technology design process? Our interest is to understand the phenomenon of information architects by understanding the commonalities and differences in their practices. In particular, we wanted to identify the HCI and usability issues that are relevant to the work of information architects and to understand how processes, broadly defined as user-centred, are being developed for, and applied to, the design of new and rapidly changing technology.

The research reported here is based on 26 intensive, loosely-structured, mostly workplace, but always work-based, interviews with people who are called and/or call themselves information architects. The first eight interviews were with known industry contacts and the other participants were recruited via a single call for participation posted on the listserv hosted by the Computer-Human Interaction Special Interest Group (CHISIG) of the Ergonomic Society of Australia. This is the Australian professional organisation for academics, researchers and practitioners in HCI and related fields. This call was in turn reposted by still unknown readers of the CHISIG listserv to a range of specialist information architecture (IA) lists and discussion groups. Most of our participants were working in Sydney and Melbourne in Australia, but five were based in Europe, one in Hong Kong and one from the US.

In the interviews we sought to identify the common issues affecting the work of information architects as well as those issues that were highly situated and domain specific in their affect on different individuals. The interviews lasted between $40 \mathrm{~min}$ utes and one hour. All interviews were fully transcribed. The interviews ranged over three main areas. The bulk of each focused on the actual work of information architects. Each participant was asked to situate their answers in their most recently completed project. This provided us with 26 examples of genuine work practice to represent what information architects actually do. We asked specific demographic questions about professional backgrounds, qualifications and ongoing professional development. Finally we asked how information architects viewed their own work and how they thought it was perceived by various others.

To our knowledge this is the only study to date of the work practices of information architects and the only study of any HCI or related practices that include mostly Australian practitioners. Our research is phenomenologically motivated [1] but because our space here is limited, we cannot give a full account of our findings nor engage in extended analysis. Our aim here is to provide a basic conceptual ordering and descriptive summary of the rich empirical data gathered in the interviews [8]. In the following section we summarise the demographic data from the study before discussing the range of work that the information architects themselves defined as part of their practices. From there, the participants view of their own work and its place within the broader design processes of their organisations is briefly examined. The paper concludes with a discussion of the benefits that a deep understanding of HCI and usability issues brings to the agency of information architects in their work practices. 


\section{Some Demographics}

The ages of the participants ranged between approximately 25 to 45 . Men and women were equally represented. Seven had worked as information architects or in closely related fields for more than five years, eight for between three and five years and the remaining eleven for three years or less. Only one participant had no university qualification. Three had no undergraduate degree but had gained, or were completing, postgraduate qualifications. Of those with undergraduate degrees, eight had first degrees in the humanities, eight in architecture/design (including one each from industrial design, graphic design and ergonomics); two had first degrees in mathematics, two in new media (digital design etc) and one in economics. None had undergraduate degrees in IT or information science. 15 had, or were completing, postgraduate qualifications; five in IT, three in new media and three had a specialist qualification in HCI. Two had postgraduate qualifications in education and two in the humanities.

None of our participants had studied information science despite its traditional contribution to information design as a discipline and its common claim to be the core discipline in the field of information architecture. We explicitly sought information architects from an information science background via the information science department at our university and through relevant professional organisations, but we were not successful. This could indicate that the claimed dominance of this discipline in the training of those who are called information architects is not reflected in the work place, at least in Australian technology design environments.

It is common for people who work in information technology design environments to come from other areas, and popular texts on information architecture emphasise its multi-disciplinarity (eg [7] especially chapter two). The professional backgrounds of our participants included: academia and research (five), web development (three), two each from HCI, instructional design, visual design, theatre, publishing and marketing; and one each from school teaching, fine arts, communication, industrial design, consulting and public relations. Despite the diversity of their backgrounds, some kind of design training and/or professional background was common to approximately half the participants. Given that information architects are such a recent phenomenon, the lack of specialist training is not surprising. But it means that there is no basic shared body of professional knowledge and skills that can be assumed for people working as information architects.

Most participants used mailing lists and specialist websites to sustain their professional development in information architecture and related areas. Round half attended industry conferences or short courses and almost all of these had attended at least one Nielsen/Norman short course in Sydney in the previous two years. A third of our participants regularly bought popular industry publications through Amazon.com and only five read academic research papers. Just over half the participants cited Garrett's ([2] [3]) definition of information architecture as the "structural design of the information space to facilitate intuitive access to content" and each of these were able to produce a copy of his 'elements of user experience' diagram [2]. Yet, as will be shown in the next section, the practices of the great majority of information architects we interviewed were far more varied than those Garrett described. 


\section{The Work of Information Architects}

During their last project, half the participants had worked on the development of a specific website (or part), six on intranets (or part), two on extranets, three on specialist web-based applications and two had worked on projects that were not webrelated. These projects were situated in a range of industry sectors including six from both government and ICT, five from finance, two each from retail, public utilities and entertainment, and one each from building/construction, real estate and the media. At the time these projects were completed twelve of our participants worked in the IT section of larger organisations, twelve were employed by smaller, specialist IT solution providers and two worked for dot.com companies. Ten of our participants were in recognised management roles.

In Table One (below) we provide a summary of the work each of the participants did in their last project. This table summarises a prior one developed from the initial interview transcripts by noting and then tabulating the activities specifically mentioned by each information architect. That table is far too big to reproduce here and we have included the summarised version in its place. The process of reducing the table to printable form was guided by our finding that all the kinds of work specifically mentioned fitted within the broad categories of Research, Focused Designing, Evaluation, Coordinating Internal and External Stakeholders and Management.

The top section of Table One maps the work practices of each participant (columns labelled $\mathbf{a}$ to $\mathbf{z}$ ) to these broad categories of work (rows). Row order is not an indication of any sequence of work during the projects. The participants rarely described their work sequentially and any time relations between the various activities that were available from the data have been lost by the process of summarising it in this way. Those working in management positions have been grouped together on the right hand side of the table. The lower section of the table records whether the individual information architect indicated a familiarity with user-centred design methods as well as their experience in their current and related jobs.

We emphasise that these categories were not imposed on the data but emerged from the iterative analysis of interview transcriptions and then validated against additional transcriptions. To give our readers some understanding of the extent of reduction in this categorisation, Research includes user, process and domain research, research of any existing applications as well as any usage statistics. Focused Designing includes practices as varied as requirements development, defining scenarios and personas, developing sitemaps and navigational models, producing wireframe diagrams, interface design, interaction design and the design and development of prototypes for evaluation. Evaluation included heuristic evaluation, card sorting, various kinds of evaluation of different kinds of prototypes, user testing of various kinds, focus groups, informal feedback, implementation reviews and project process reviews. Coordinating internal and external stakeholders included working as the project's communication facilitator, liaising with content providers, liaising with external providers, preparing and delivering presentations and customer pitches as well as the range of activities usually covered by 'attending meetings'. Finally, Management work included defining the overall design process, managing that process, managing the project itself and/or the people 
working on it. Some grounding discussion of the work represented in Table One makes up the remainder of this section.

Table One. Summary of the work done by information architects in their last projects

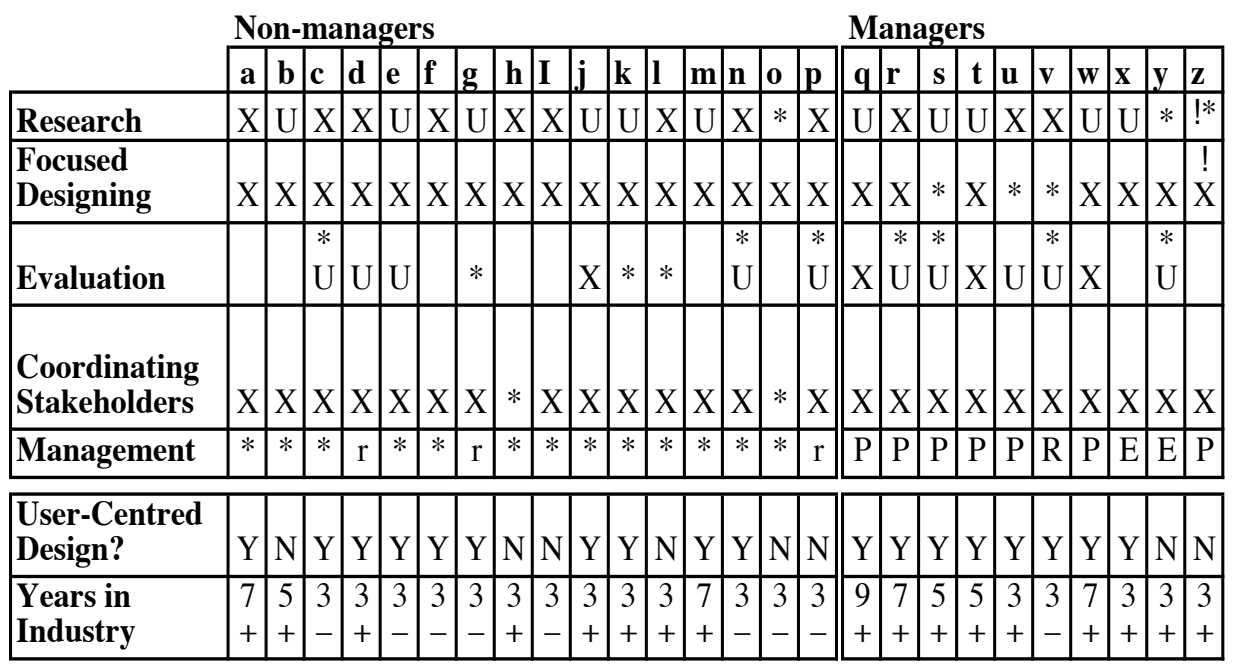

Notes for reading this table.

$\mathrm{A} *$ indicates that the work was done on the project but not by the information architect. $\mathbf{X}$ indicates the individual architect was involved in these work practices. $\mathbf{U}$ indicates users were also involved. $* \mathbf{U}$ means someone else did this work but users were involved.

A space in the Evaluation row means that no evaluation was done on the project.

In the Management row, $\mathbf{P}$ means the person managed the people and the process, $\mathbf{R}$ means they managed the process only, $\mathbf{E}$ means they managed the people only. $\mathbf{r}$ in the nonmanager columns means that person managed the process but was not officially recognised. In the User-centred Design row, $\mathbf{Y}$ means Yes, this information architect knew about usercentred design methods, $\mathbf{N}$ means No, they didn't.

\subsection{Research}

Information architects were as involved in various kinds of research about the developing product as they were in specific design processes. One of the participants specifically compared her work as an information architect to research work.

The ability to pose the question is the crucial thing. And then the ability to determine what an appropriate solution to that problem would be. And then the ability to define the methodology to get from there. Very similar to research, what you're doing at the moment. You're trying to pose the question: what should be actually focused on within all the confusion and messiness? (Interview b).

When user research was done in a project, the information architects either did it alone, with specialist user experience modellers working under various job titles, or 
used the results from the work of these people. Most participants were also involved in both domain research and research into the use of any existing technology.

\subsection{Focused Designing}

We considered Information Architecture as the label for this category this did not specifically cover design work, such as scenario design, prototype development and interface and interaction design, which is common to information architects as well as those employed under other related job titles such as interaction designer, user experience modeller etc. This category is defined by the production of specialised design representations within each of the activities included in it. We eventually settled on Focused Designing, rather than just Designing because this study demonstrated that actual technology design practice includes the full range of work summarised in Table One and that the production of design representations is just one part of this practice.

Only half the participants were responsible for 'traditional' information architecture areas such as the production of navigation models and wireframe diagrams. But none worked only on these activities and none spent most of their time on this work. The information architect represented in column $\mathbf{o}$ is the only person whose work was restricted to processes categorised here as Focused Designing. She was the most junior information architect we interviewed and worked within a specialist provider company with a task-based organisational structure. But even her work also included interface and interaction design. Only three information architects were not directly involved in the focused designing but they were responsible for the management of their projects.

\subsection{Evaluation}

Our participants were less likely to be directly involved in the evaluation of the product (only seven of the 26). Our findings provide two explanations. The first is that some organisations either had people dedicated to usability evaluation in the design team or routinely outsourced those parts of the process to a specialist provider. The second is that in nine of the 26 projects ( 35 percent) no evaluation was done at all. Just over half the products that were evaluated involved users in that process (round 40 percent of the total). Relying on informal feedback throughout the design process was the most frequent evaluation method. We are aware that some in the HCI community would not consider informal feedback as evaluation at all but it is included in this category because the information architects in our study explicitly referred to informal feedback as one of the ways, sometimes the only way, their products were evaluated.

\subsection{Coordinating Stakeholders}

The centrality of the coordination of stakeholders to the work practices of information architects is one of the major findings of our study, confirming [6] and others' findings that the technology design process relies on the communication work done by design- 
ers to coordinate their work with the work of others. This is the activity that occupied most of the time of the information architects we interviewed and was regarded by almost all of them as defining of their work practice. Of the two information architects who were not involved in stakeholder coordination, one is the junior staff member referred to above and the other (column $\mathbf{h}$ ) was building an already specified application to work on an existing web-site. He was a programmer on contract who had called himself an information architect (by ticking that box on an online cv generator) in order to get a job in web design work.

Most importantly, this coordination work is where the politics of the design process is played out and where usability gains are won and lost. Perhaps the most sobering theme to emerge from our interviews was the sense of technology design as some kind of struggle, or at least a competition. Participants described a range of projects where the final design was not shaped by any particular design method but instead by competition, from different parts of the organisation designing the technology and/or the client organisation, for control of the process, for control of budgets, for control of content and for control of how different parts of the organisation were represented within the product itself.

\subsection{User-centred Design Processes and Methods}

18 (70 percent) of the information architects noted an understanding of, and experience in, developing design concepts using direct user involvement. Yet only twelve of the 26 projects included user research of some kind, only eight involved users in the product evaluations and just two involved users in both. Our findings confirm those of Vredenburg et al. from their extensive survey of user-centred design practices [9]. They wrote: "Some common characteristics of an ideal user-centred design process were not found to be used in practice, namely focusing on the total user experience, end-to-end user involvement in the development process, and tracking customer satisfaction" (p. 478). Eight (30 percent) of the participants either did not appear to be familiar with user-centred design processes, or while they may, in fact, have involved their users, they were unable to situate this involvement within the wider, established design methods for user involvement. An inspection of the Years in Industry row of Table One identifies seven of these participants as among the least experienced of the information architects. These information architects were also notable as having the least control over the design priorities in the products they were building relative to the other participants.

A third of the information architects explicitly noted that user involvement was the first item to be removed from the budget when things got tight. The resulting product design was based on assumptions about the user, not on genuine user participation. This applied even to those working within specialist service providers with established user-centred design processes who still faced unwillingness from clients to pay for user participation or to make potential users available to the design team. The information architect was expected to be able to represent the user in the design process. This 
meant an increasing reliance on discount usability methods and the use of information architects as user-representatives in the design process.

\subsection{Information Architects as Managers}

We have separated those in recognised management roles to make visible our finding that users were more likely to be explicitly involved in the design process when information architects were involved in management work. This was the case even when their management role was not officially recognised. Two managers did not express familiarity with user-centred design methods. One (column y) came from a product design background and was responsible only for people management within a specialist provider company that marketed itself on its user-focused design process. The other (column $\mathbf{z}$ ) had chosen the title of information architect for strategic reasons and was rarely involved in the actual design of specific products. His main work was stakeholder co-ordination in a mid-size specialist IT service provider. Four of the managers had developed their own variations of user-centred processes that were being used, with various degrees of wider commitment, within their companies and one had been explicitly employed to demonstrate how user-centred methods might improve the quality of the organisations products. The importance of management clout and support to the involvement of users, and user-centred processes, in product development was one of the strongest issues that emerged from our analysis. Those working in management roles were also able to protect information architects within their teams and facilitate their work in the broader organisation.

\section{Information Architects' Perceptions of Their Own Work}

While the great majority of those interviewed were working in web design of one kind or another, the term information architect did not define a uniform and discrete role in the design and development process. Information architects did a variety of work and all participants saw their work as pivotal to the design process in their organisations. None of them gave definitions that were as tightly focused as those from the literature that have already been quoted in this paper [2] [3] [4] [10]. No one represented their work in terms of the production of site maps, wireframe diagrams or navigation models. Neither did they represent it in terms of meetings, research or the coordination of stakeholders. Instead they described a role that was defined by its fluidity, its place filling the gaps, holding both the process and the product together, reflecting a sense of ownership of, and responsibility for, a particular aspect of the final product. The part of the product most often claimed was 'its bones' and the corresponding relationship to the usability of the product.

It kind of defines that stuff that happens in between all that other stuff. I try and make things simpler for people to use (interview a).

So much of my job is about clarifying roles. Everybody says, "I don't know why I'm doing this, this is not my job to do, this is not my job to do" and it seems to 
be like this missing role and until you have somebody that comes in and says,

"I'm an IA. Give that to me" (interview b).

Basically you work in between the rocks and the hard places (interview q).

I'm sort the meat in the sandwich (interview c).

A lot of I.A. is just a struggle for clarity (interview e).

I see it as a lynch pin between a lot of the other disciplines (interview $f$ ).

This role had no edges (laughs) (interview $g$ ).

Participants varied in their acceptance of the term information architect to describe their work. On the whole, those with the least experience were less likely to be reflective about the appropriateness of their title. These information architects were often the most recent graduates with qualifications in multimedia or new media design. Their professional experience had not included the period before information architect was used as a job title and they appeared to take for granted that it named what they did. Each participant with more than three years experience in the field said they had been called a range of titles in their careers but had done similar work (most frequently described as interaction design) in each. One participant commented that that the term was so associated with the dot.com boom that he wondered if it might disappear "along with the other excesses of that time" (interview m). Another commented:

I don't think that the role is necessary. I think that as a step in the design process, working out the information architecture and interaction design of the system is absolutely necessary, but the person that does that and performs that task doesn't necessarily have to be an information architect (interview $x$ ).

The slipperiness of the definition of the term did not appear to matter greatly to the information architects themselves. It was used strategically in some cases to cover a gap in the process, especially in relation to user involvement. It was used without reflection but also without apparent harm in others. But it always appeared to name some space, sub-process or role in the design process that needed a name.

\section{Information Architects and HCI Practice}

Those information architects able to reflect on and articulate their work practices displayed a real passion for the quality of the user experience of the final product and a desire to infuse the traditional software engineering approach with more user-centred approaches. What differed was the ease with which they managed to shape the usability of the final product within the other constraints of their organisations. Such organisational challenges are not unique to information architects but common to all those committed to user-centred design. The most successful and influential in our study were experienced professionals, usually working in management positions, who knew a great deal about HCI issues and usability principles.

Knowledge of HCI issues and usability principles emerged as one of the key elements that enabled participants to take more control over the design process used in their organisations. Those information architects most influential in their organisations were those who read research papers, who had research skills, who read beyond the popular titles on usability and web design and who worked actively within relevant 
professional associations. These information architects were more able to effectively argue for the value of user-centred processes within any kind of design process in any kind of organisation. At the same time they were sufficiently flexible in their own practices that they could select those user-centred processes and methods that were most likely to be successful. They were prepared to, and able to, undertake as many different design and evaluation methods as needed and had managed to find ways to make space for their users in even the most hostile environments: "We have a tendency to use guerrilla usability tactics" (interview s).

These information architects also played an active educative role, promoting the practice of information architecture within their work setting and to other industry practitioners. This took various forms; some tutored in HCI and related subjects at their local university; others spent time training work colleagues in analysis and design techniques they would use themselves; one even taught his colleagues and users how to use heuristics to evaluate the developing application. Sharing knowledge proved for some to be an effective way to promote a greater understanding and appreciation of the work that they did both with other members in their project team and those in the wider organisation.

\section{Acknowledgements}

We are most grateful to those information architects who participated in this research. We also thank Sam Harvey and Jenny Edwards for their contributions to this project.

\section{References}

1. Crotty, M.: The Foundations of Social Research. Allen \& Unwin, Australia (1998)

2. Garrett, J.: The Elements of User Experience. Diagram retrieved January, 2004, from http://www.jjg.net/elements/ (2000)

3. Garrett, J.: The Elements of User Experience. New riders Publishing, USA (2002)

4. Preece, J., Rogers, Y. and Sharpe, W.: Interaction Design: beyond human-computer interaction. John Wiley, USA (2002)

5. Preece, J., Rogers, Y., Sharpe, W., Benyon, D., Holland, S. and Carey, T: HumanComputer Interaction. Addison-Wesley, UK (1994)

6. Robertson, T.: Embodied Actions in Time and Place: The Cooperative Design of a Multimedia, Educational Computer Game. Computer Supported Cooperative Work:, Vol 5, No 4.Kluwer Academic Publishers, Dordrecht The Netherlands (1996) 341-367

7. Rosenfeld, L. and Morville, P.: Information Architecture for the World Wide Web. O'Reilly, USA (1998)

8. Strauss, A. and Corbin.: J. Basics of Qualitative Research. Sage Publications, USA (1998)

9. Vredenburg, K., Mao, J., Smith, P. and Carey, T.: A Survey of User-Centred Design Practice. In CHI Letters, Vol. 4, No. 1, 471-478. ACM, USA (2002)

10. Wurman, R.: Information Architects, Graphic Press Corp, Switzerland (1996) 